\title{
Research on the Emphasis and Strategies of Tourism Public Service Supplies under the State of Crisis
}

\author{
Zou Zaijin $^{1}$ Gan Kaipeng ${ }^{2}$ \\ ${ }^{1,2}$ School of Public Management, Yunnan University of Finance and Economics, Kunming, \\ P. R. China, 650021 \\ (E-mail: spa3238@163.com)
}

\begin{abstract}
The tourism public service supplies refer to the fundamental and non-profit tourism public goods and services provided by governments (especially the tourism departments) according to the public needs of tourism. Under the state of crisis, the needs of the public and society for tourism public services supplies are urgent and unusual. In this background, the paper analyses the emphasis of tourism public service supplies from the perspective of the constitute of tourism public service and puts forward the strategies to strengthening the tourism public service supplies in the state of crisis.
\end{abstract}

Keywords: Tourism, Public Crisis, Public Service

\section{Introduction}

In recent years, the crisis incidents become more and more prominent in the field of tourism with varied manifestation such as the vicious incident that twenty tourists were chopped wound by guide in Lijiang, Yunnan province on April 1, 2007, the serous violent crime incident that was launched by gangs of
Uighurs to indiscriminately attack on passers-by and damage property on March 14, 2008 in Lhasa, Tibet, the event with heavy casualties that caused by traffic accident between Shanghai and Changshu on April 22, 2012, and so on. These crisis incidents not only had caused heavy losses of personal injury and property damage for tourists, but also brought serious negative influence on the tourist image, which queried the governments' ability to provide tourism public service. However, the research on tourism public service supplies under the state of crisis is still weak among domestic academic group at present. Due to the insufficient attention, the limit literature only focused on the strategies of public governance [1], the governments' ability to control information and media under the state of tourism crisis [2] and the coping strategies of tourism crisis caused by natural disasters from the perspective of individual case [3], instead of the issues of tourism public service under the state of crisis. The research on tourism public service in domestic academic circle which is related to tourism public crisis or unexpected tourism incidents is little, so this study is necessary and has very important realistic meanings. 


\section{The Constitute of Tourism Public Service and its Emphasis in the State of Crisis}

\subsection{The constitute of tourism public service}

Tourism public service refers to the fundamental and non-profit tourism public goods and services provided by governments (especially the tourism departments) according to the public needs of tourism. The public need of tourism is the objective require existing in tourism departments which determines the activities scope of tourism departments. With the proposal of a service-oriented government, it has far-reaching implications for the administrative authority of tourism to meet the tourism public needs, strengthen the construction of service-oriented government and promote the tourism public service, which will push forward the sound and rapid growth of tourist industry and realize the object of a strong country with a developed tourist industry in the world.

Tourism public service providing by government (especially tourism departments) is a relative complex system which consist of three parts [4].

\subsubsection{Fundamental tourism public service}

Tourism public service is a kind of indiscriminate public service provided by governmental public departments for all the social members to consume and enjoy. It includes: (1) the construction of infrastructure facilities in the field of tourism, such as transportation facilities, public landscape, environmental construction, traffic, leisure facilities in tourist areas; (2) public information platforms of tourism which refers to the nonprofit and essential information service orienting to society, markets, tourists, tourist enterprise and practitioners, such as the roads and sign system of tourist facilities in tourism destination, Tourist Information Center and the distribution system of tourist information; (3) the construction and protection of eco-tourism, such as the restoration and construction of ecology and vegetation in some major tourist areas, the construction of infrastructure facilities in environmental protection in tourist towns and the environmental protection of key heritage; (4) the tourism public service which includes the educational training of tourism, such as the personnel training of tourism professional, the vocational skills training and the tourists' quality education, and the social functions of tourism, such as the promotion of tourism employment and poverty-relief and so on.

\subsection{2. the market tourism public service}

Tourism public service not only can meet the public needs, but also the needs of enterprises and individuals, so it can absorb the common participation of enterprises and NGOs to provide tourism public services through market competition. These tourism public services include: (1) the development and administration of tourism public resources, such as the formation of regional tourism development planning, the development and administration of natural and cultural heritages and the development and use of related tourism resources; (2) the guarantee of tourism public security, such as the tourism safety assessment and precautions, tourism infrastructure construction, emergency relief of unexpected tourism public incidents, and international cooperation of tourism safety; (3) the tourism communication, cooperation and propagation, such as the propagation of tourism destination image, the marketing strategies of special tourism products, the international tourism cooperation, and large-scale tourism commonweal activities; (4) 
the promotion of tourist consumptions and well-being, such as the increasingly optimized tourist consumption environment, consumer protection and various tourism benefit policies.

2.1.3. The administrative tourism public service

The administrative tourism public service aims to maintain the fair of tourist business, establish orderly tourism market, and develop administrative tourism public service. It includes: (1) the necessary examination and approval, of market entry, check, and annual verification for enterprise and individuals which engage in tourism business, such as the business license of tourist agency, and guide regulations; (2) formulating and disseminating national codes and standards of tourism services; (3) the administration and administrative penalty for the illegal management behavior; (4) coordinating the NGOs' cooperative activities.

\subsection{The emphasis of tourism public service supplies in the state of crisis}

Due to the unexpectedness, urgency, uncertainty, and social influence of tourism public crisis, the system construction of tourism public service in the state of crisis not only can not limit to normality, but also should surpass the normal state, so as to benefit the crisis alarming, judgment, apartheid, administration and coping with the aftermath of a crisis. It also should strengthen the tourism public goods supplies in some major fields, guarantee the minimization of negative influence of tourism public crisis and ensure the best state of tourism public service after the aftermath of a crisis.

Because of the different characteristics of tourism public crisis with different nature, the emphasis of public service supplies also are various. It includes: (1) as for tourism public crisis caused by natural disasters, it should focus on the essential tourism public service supplies, especially the construction of tourism infrastructure facilities and the construction and protection of eco-tourism; (2) as for tourism public crisis caused by accidents, it should focus on the market tourism public service and administrative tourism public service, strengthen the guarantee of tourism public safety and strict market entry, actively disseminate national codes and standards of tourism services, and attack illegal management behavior; (3) as for tourism public crisis caused by public health, it should emphasize the essential tourism public service supplies, especially the construction of public information platforms of tourism and the development of tourism public service as well as the tourism communication, cooperation and propagation; (4) as for tourism public crisis caused by social safety, it should focus on the market tourism public service and administrative tourism public service, especially the strengthening of tourism public safety, the improvement of tourism regulations and the self-discipline in tourist industry.

There is different needs of tourism public service supplies for society and tourist industry under the sate of crisis, so the governments at all levels and tourism administrative departments should set up the awareness of crisis, and construct the system of tourism public service in a planned, manner. During the normal state, it should focus on the whole construction and improvement of tourism public service supplies system, while the tourism public service supplies in some major fields should be emphasized under the state of crisis. At the same time, governments at all levels also should actively explore the 
response mechanism of tourism public service under the state of crisis and improve the ability of public crisis precaution, control and restoration which is influenced by the tourism public service.

\section{The Strategies to Strengthen the Tourism} Public Service Supplies under the State of Crisis

According to the evolving characteristics of tourism public crisis, the tourism public crisis can be divided into four independent periods, namely, omen phase, emergency phase, lasting phase and recovery phase.

Omen phase is a period in which various omens tend to cluster before the tourism public crisis; emergency phase is a period in which the tourism public crisis already happened and evolved rapidly; lasting phase is a period in which the tourism public crisis has been distinguished and controlled; while recovery phase is a period in which the crisis or incidents have been settled completely, the restoration work is implemented successfully, and the social values and behavior code return to normal state. Due to the different characteristics of four development phases of tourism public crisis, governments (especially tourism departments) should provide different contents through different ways.

\subsection{Omen phase}

The tourism public crisis supplies system under the state of crisis, execution system, which includes decision-making system, coordinate system, auxiliary system, advice systems, should be established. The emergency action plan of tourism public crisis should be formulated, so as to strengthen crisis surveillance, maintain communication open, and distinguish crisis at time. At the same time, the tourism public crisis supplies which are provided by governments (tourism departments) should be guaranteed from organizational structure, crisis control plans, and so on.

\subsection{Emergency phase}

It should carry out emergency action plan of tourism public crisis, promote the full response and effectively operation of tourism public service supplies, emphasize crisis decision-making, optimize the allocation of resources and social coordination, establish public information platforms of tourism, guide the public opinions, function adequately the role of governments at all levels (especially tourism departments) in the tourism public service supplies, and minimize the loss.

\subsection{Lasting phase}

The governments at all levels (especially tourism departments) should find the sources and spread ways of crisis at time, actively adopt effective measures to hinder the development of crisis, adopt effective segregating actions through various physical ways under necessary circumstances. Meanwhile, the victims should be relieved and assisted at time through necessary psychological intervention; the property should be recovered, so as to maintain the social order and social stability by finding social assistance, propagation, communication and cooperation.

\subsection{Recovery phase}

The governments at all levels (especially tourism departments) should adopt various measures to settle crisis, formulate strategies to plan the long-term development, implement the recovery and restoration of production, living facilities and social order, investigate 
the reasons of crisis and look into the responsibility for the tourism public crisis, and summarize the experiences and lessons from tourism public crisis. In recent years, the development of "black tourism" is a kind of beneficial explore for the handle of crisis, which provide a new perspective for the improvement of governmental public service supplies during he recovery phase.

\section{Conclusion}

With the increasing break-out of pubic crisis in the fields of tourism, it is very important for governments (especially tourism departments) to strengthen the tourism public service supplies under the state of crisis. The tourism public service supplies under the state of crisis should focus on different emphasis according to the different nature of tourism public crisis, instead of the whole construction of tourism public service supplies system. Due to the four evolving development phase of tourism public crisis, the governments at all levels (especially tourism departments) should form the strategies of public service supplies which are according with the four development phase of tourism public crisis.

\section{References}

[1] Mao Jinru. Discussion on Tourism Public Governance from the perspective of Public Policy: a Case Research on Crisis Management [J]. Journal of Guilin Institute of Tourism, 2009, 2 (3) : 424-427(in Chinese)

[2] Ma Tengfei, Li Jianming. Analysis on the Governmental Ability to Control Information and Media in Thailand Tourism Crisis [J]. Around Southeast Asia, 2006, (11) : 56-59 (in Chinese)

[3] Tian Ming. Thinking about the Tourism Crisis after Huge Earthquake: Based on Governmental Dimension [J]. Special Zone Economy, 2008, (11) : 154-155(in Chinese)

[4] Liu Xiaojun. Thinking about Some Issues of Strengthening Tourism Public Service [J]. Tourism Research, 2007(9):11-13 (in Chinese) 